\title{
Complexity of Decisionmaking in Infrastructure Investments in Albania
}

\author{
PhD. Fioralba Vela \\ University of Vlora, Albania \\ Email:fiorivela@yahoo.it \\ PhD candidate. Migena Petanaj \\ University of Vlora, Albania \\ Email:migenapetanaj@hotmail.com \\ Msc. Lorena Cakerri \\ University of Vlora, Albania \\ Email: lorytaraj_22@yahoo.it
}

\section{Doi:10.5901/mjss.2013.v4n2p199}

\section{Abstract:}

The purpose of this paper is to understand the complexity of the decision-making process in infrastructure investment in Albania, particularly in PPP arrangements: to understand to what extent this complexity actually exists and how the government as a key actor deals with these new environments. It is used a network perspective as a framework for study and the Rounds Model (Teisman, 2000) as a point of departure to analyze the complexity of decision making in infrastructure investment. The paper contributes to the discussion on complexity in the context of developing countries, as Albania, with reference to the configuration of actors in the policy network.

Key terms : decision-making, complexity, round model, Albania

\section{Introduction}

Although discussions on the effect of infrastructure on the economy are interesting for both scholars and policymakers, infrastructure planning and decision making are, in fact, not simple processes. Decision making for infrastructure such as building roads, ports, and other major public works is becoming more complex. The issues that need to be considered are not only technical and economic, but also environmental and political. There is a trend all over the world for citizen involvement in decision making. In line with this trend, governments are exploring different types of planning and decision making that consider the increased interdependency of actors. Concepts such as interactive planning, network management, stakeholder dialogue, community governance, open-planning procedures, and participatory planning have emerged (Arts \& Tatenhove, 2005; Edelenbos \& Klijn, 2006; Woltjer, 2002).

In the present globalized era, we live in a networked society. Any policy, any strategy, any human project, has to consider this basic fact (Castells, 2006). It is little wonder that decision making has become more complex. Problems cannot be solved by organizations on their own. As a consequence, hierarchy as an organizational principle has lost much of its meaning, with horizontal networks replacing hierarchies (Koppenjan \& Klijn, 2004). As Birkland (2001) said, intuitively we can understand that actors in the policy process can and must interact with each other to advance policy proposals.

Without this interaction, nothing would happen, and policymaking would come to a standstill. Organizations and individuals who are participants in complex decision problems interact in an environment in which conditions are often changing rapidly and unpredictably, which increases the uncertainty experienced by participants dealing with decision problems (Radford, 1978). 
These issues not only affect developed countries but also countries in transition like Albania, which have become democratized. Reform occurs not only in the political system but also in public administration and public finance, together with a decentralization policy. Even though discussions on new perspectives on decision making usually take place in Western countries, it is quite interesting to explore the possibility of using a variety of analytical approaches in a newly democratic country such as Albania, where the concept of participatory planning and citizen involvement has been growing (Dasgupta \& Beard, 2007; Timothy, 1999). However, it is also important to note that political, socio cultural, and economic environments in Albania are different from those in Western countries.

\section{Literature review and hypothesis}

Process analysis and decision making process analysis receive a lot of attention in the field of political sciences and public administration. Theoretical developments in those academic disciplines have made a valuable contribution to researchers working with planning and policymaking to cope with environment and spatial issues and problems.

In analyzing decision making, we need to reconstruct the study object. Decision making cannot be depicted without making assumptions about its appearance (Teisman, 2000). Terms such as framework and model have been used to define approaches to address the topic of policy process analysis. Models of a policy process can help us to learn what is most important in the policy process (Birkland, 2001).

Various approaches have been developed as a foundation for either a policy process or a decision -making process analysis. Sabatier (1991) noted that there are four frameworks: the open systems framework of Richard Hofferbert, an approach involving rational actors within institutions developed by Elinor Ostrom and her colleagues, John Kingdon's "policy streams" framework, and his own "advocacy coalition" framework. In addition to those frameworks, there are also more models like Birkland (2001), who noted the garbage can model developed by Michael Cohen, James March, and Johan Olsen (1972). Teisman (2000) elaborates on three models: phases, streams, and rounds. Monnikhof (2006) reviews four models and their relevance to the Netherlands: network theory, garbage can and stream theory, the rounds model, and the advocacy coalition framework.

Each framework or model has its own assumptions. It should also be noted that researchers have developed these models based on case studies in developed countries. Therefore, the contextual aspects should be considered before applying the model for analysis in Albania.

The main question raised in this paper is:

$>$ How are infrastructure investment decisions formulated? This question includes the following sub-questions:

$\checkmark \quad$ Who defines the need for new infrastructure investment in Albania?

$\checkmark$ What goals of new infrastructure investment have emerged?

$\checkmark \quad$ Whose goals have emerged?

\section{Research method}

In order to find a model that suits the context of analysis, we will briefly present three of the most prominent approaches for decision-making process analysis: the policy network approach, the advocacy coalition framework, and the rounds model.

\subsection{Policy Networks}

Basically, the network perspective on public policy sees policy as being formed through interactions between different actors who have their own perceptions and strategies (Edelenbos \& Klijn, 2006). The core of this perspective is a decentralized concept of social organization and governance: society is no longer exclusively controlled by a central intelligence; rather, controlling devices are dispersed, and intelligence is distributed among a multiplicity of action (or "processing") units. The coordination of these units is no longer the result of "central steering" or some kind of "pre stabilized harmony" but emerges through purposeful action by exchanging information and other relevant resources (Marin \& Mayntz, 1991).

In the literature on governance, the concept of policy network could be located somewhere beyond or between the market and hierarchies (Kenis \& Schneider, 1991). In relation to decision-making processes, many decisions in the public sector have to be made in networks that consist of various actors who are mutually dependent and have diverging interests (de-Bruijn, 2005). 


\subsection{Advocacy Coalition Framework}

The advocacy coalition framework (ACF) was developed by Sabatier (1988). Its goal was to provide a coherent understanding of the major factors and processes affecting the overall policy process, including problem definition, policy formulation, implementation, and revision in a specific policy domain-over periods of a decade or more.

The ACF was developed upon a policy subsystem that is also known as a part of network theory. Various terms have been used by scholars, such as policy network, policy community, policy subsystem or policy domain (Coleman \& Perl, 1999).

\subsection{The Rounds Model}

Teisman (2000) has compared and elaborated three models: the phase, the streams, and the rounds model in the Netherlands. The phase model focuses on successive and distinctive stages in a process, i.e. defining a problem, searching for, choosing and implementing solutions. The stream model emphasizes concurrent streams of participants, problems and solutions, defining decision making as the connection between these streams. Teisman then emphasized the third approach, the so-called rounds model, which assumed that decision making consists of different decisionmaking rounds.

Teisman (2000) argues that the added value of the rounds model as compared to the phases and streams models can be summed up in three points.

- First, in term of actors, problems, and solutions, the rounds model focuses on the interaction between actors, during which they can negotiate acceptable combinations of problems and solutions. In the rounds model, decision making is not about a single issue, or about separated streams of problems, solutions, and participants, but about dynamic combinations of sets of problems and solutions represented by different actors.

- Second, in terms of policy adoption, yardsticks, or results, a round begins and ends with the adoption of a certain combination of a problem definition and a (virtual) solution by one or more actors.

- Third, in terms of policy evaluation and evaluation criteria, evaluation in the rounds model no longer focuses on the question of whether the policy result agrees with a single policy intention, but whether the result responds to the objective of all the parties involved at the moment policy effects can be distinguished.

Figure.1: Teisman's version of the concept of decision making in the rounds model. 
In the foregoing section of the paper, there are discussed three conceptual models or frameworks, that are found in the decision making process analysis literature. In regard to the large number of existing frameworks for decision-making process analysis, it is important to avoid creating and adding new ones unnecessarily. The most fruitful strategy would be to take the rounds model as the starting point, since it explains the complexity of the decision-making process. The advantage of the rounds model is that it focuses on the interaction between actors, and covers dynamic combinations of sets of problems and solutions in the decision-making process.

Since the paper aims to elaborate the complexity of the decision making process, the authors have avoided binding themselves too dogmatically or rigidly to one model or approach, as each model has its own assumption. The aim is not to validate a preferred theoretical approach; rather, to borrow the model that has relevance in the context of the study in this paper. In addition to the rounds model, the policy network approach could complement the analysis.

To conduct the analysis, in this paper is adopted the rounds model (Teisman, 2000) to identify the rounds of decision making and the actors involved in the case of KESH Albania privatization by CEZ distribution operator. To get an insight into the actors and their interaction, an analysis of actor and arena of decision making is undertaken following Koppenjan and Klijn (2004).

\section{Case study : privatization of KESH Albania by CEZ distribution operator}

At the beginning of the economic transition in the early 90s Albania was a net power exporter, but by the 1998, growing demand had turned the country into a net importer. The sector had been unable to keep up with the growing demand because of low generation capacity, over-reliance on hydroelectric power, and transmission and interconnection constraints that limited the amount of electricity import procedures.

To secure the supply of electricity, the government decided to undertake a series of initiatives along with policy and regulatory reforms. In the tables below, are presented the empirical events and the course of action taken by the actors in the KESH privatization case in Albania, which lead to an analysis of the decision-making processes, from which a number of conclusions can be drawn.

Table. 1: Decision making rounds

Main empirical events

Albanian government asked for help World Bank to strengthen the legal and institutional framework for PPP's and to implement transactions in the key infrastructure sectors (January 2007)

DevCo and the Private Enterprise Partnership for Southeast Europe Infrastructure supported the advisory work. This ends the second round, which brought to the presentation of recommendations on the transaction and on the structure of the electricity market to the government and the regulatory framework.(December 2007).

A bidding process was launched in May 2008 and four strategic investors were prequalified: ENEL, Italy, EVN and Energi - Steiermark, Austria and CEZ operator of Czech Republic. Only ENEL and CEZ passed to the final stage.

Albanian government and CEZ since the winning of the bid from the last one began the negotiations related to the way of operation in the energetic market.

\section{Interpretation based on the rounds model}

The first round: exploring an action to anticipate future problems and the need for transport infrastructure. The government retained IFC as its lead advisor for the process of unbundling and privatization of the electricity distribution sector.

Second round: allowing the monopolistic situation in the business of electricity distribution, giving to the private partner a chance for a better ROI., necessary for innovating and developing the network.

Third round: the bidding process was launched in May 2008 and four strategic investors were prequalified. The process was concluded successfully in October 2008 with the selection of the CEZ group of the Czech Republic as the winning bidder for the acquisition of $76 \%$ of the shares of the electricity distribution business.at the end of the third round in November 2008.

Fourth round: Albanian government and CEZ signed the agreement in March 2009, with a partial risk guarantee ( a World Bank financial instrument to backstop regulatory and political risks) wich was provided to mitigate the risk of noncompliance by the regulator.

Table. 2:Main actors in each round of decision-making 


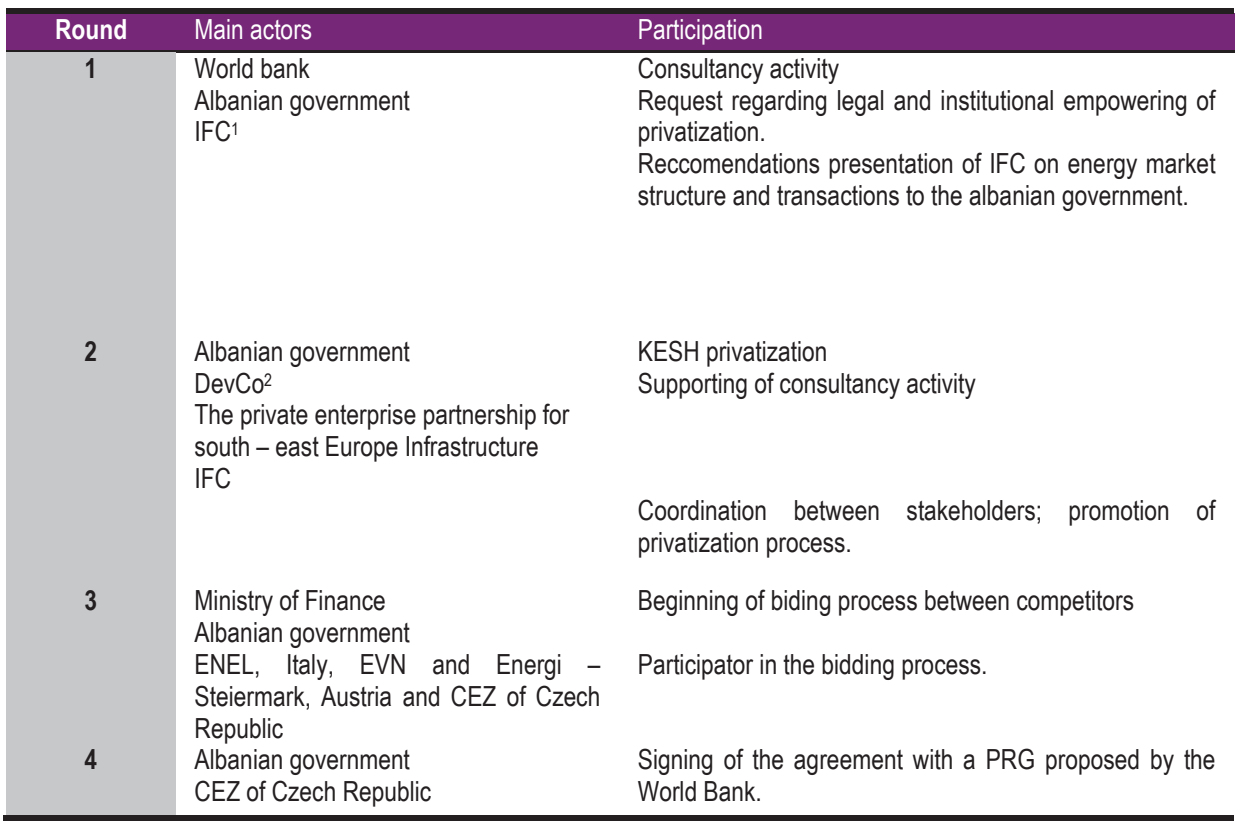

Table 3. Arena analysis

\begin{tabular}{llll}
\hline Arena & Round & Main actors & Activity \\
\hline Planning arena & 1. & IFC & Preparation of a new concession law \\
PPP arena & 2. & $\begin{array}{l}\text { Albanian government } \\
\text { Albanian government } \\
\text { Private company }\end{array}$ & $\begin{array}{l}\text { Exploring of a private- public partnership for } \\
\text { energy infrastructure investments. }\end{array}$ \\
\hline
\end{tabular}

\section{Conclusions and recommendations}

This paper examined the decision-making process of infrastructure through PPPs. The conclusion drawn was that it has become more complex. Based on a analysis of the case study : privatization of KESH Albania by CEZ distribution operator, the study found evidence that, in line with social and environmental changes, decision making could be seen as a series of rounds where decisions are taken in various arenas as a series of interactions among multiple actors involved in the network.

One of the apparent implications is that network analyses are also becoming increasingly significant for the planning and decision making of infrastructure in the current era of governance. The perspective of governance as network steering (Klijn \& Koppenjan, 2000; Koppenjan \& Klijn, 2004) recommends the participation of stakeholders in policymaking because of the interdependency between actors. Government and business, both control sources that are necessary to spatial investments and other policy (Oosten \& Esselbrugge, 2004).

From this point of view, the design of policymaking for infrastructural investment and PPPs particularly should be more sensitive to the real characteristics of the decision-making process.

\footnotetext{
1 International finance corporation

2 Infrastructure development collaboration partnership funds
} 


\section{References}

Arts, B., \& Tatenhove, J. v. (2005). Policy and power: A conceptual framework between the 'old' and 'new' policy idioms. PolicySciences, 37, 339-356.

Birkland, T. A. (2001). An introduction to the policy process: Theories, concepts, and models of public policy making. Armonk, NY: MESharpe.

Blom-Hansen, J. (1997). A new institutional perspective on policy networks. Public Administration, 75, 669-693.

Borzel, T. A. (1998). Organizing Babylon - on the different conceptions of policy networks. Public Administration, 76, 253- 273.

Castells, M. (2006). The network society: From knowledge to policy. In M. Castells \& G. Cardoso (Eds.), The network society: Fromknowledge to policy. Washington, DC: Johns Hopkins Center for Transatlantic Relations.

Coleman, W. D., \& Perl, A. (1999). Internationalized policy environments and policy network analysis. Political Studies, 47(4), $691-709$.

Edelenbos, J., \& Klijn, E.-H. (2006). Managing stakeholder involvement in decision making: A comparative analysis of six interactive processes in the Netherlands. Journal of PublicAdministration Research and Theory 2006, 16(3), 417-446.

Edelenbos, J., \& Klijn, E.-H. (2007). Trust in complex decisionmaking networks: A Theoretical and empirical exploration. Administration \& Society, 39(1), 25-50.

Keeney, R. R., \& Raiffa, H. (1976). Decisions with multiple objectives: Preferences and tradeoffs. New York: John Wiley \& Sons.

Kenis, P., \& Schneider, V. (1991). Policy networks and policy analysis: Scrutinizing a new analytical toolbox. In B. Marin \&

Klijn, E.-H., \& Koppenjan, J. F. M. (2000). Public management and policy networks: Foundations of a network approach to governance. Public Management, 2(2), 135-158.

Klijn, E. H. (1997). Policy network: An overview. In W. J. M. Kickert, E.-H. Klijn \& J. F. Koppenjan (Eds.), Managing complexnetworks. London: Sage.

Klijn, E. H., \& Teisman, G. R. (2003). Institutional and strategic barriers to public-private partnership: An analysis of Dutch cases. Public Money \& Management, 23(3), 137-146.

Marin, B., \& Mayntz, R. (1991). Introduction: Studying policy networks. In B. Marin \& R. Mayntz (Eds.), Policy networks:Empirical evidence and theoretical considerations. Frankfurt: Campus Verlag.

Radford, K. J. (1978). Decision-making in a turbulent environment. The Journal of the Operational Research Society, 29(7), 677682.

Rhodes, R. A. W. (1996). The new governance: Governing without government. Political Studies, 44(4), 652-667.

Sabatier, P. A. (1988). An advocacy coalition framework of policy change and the role of policy-oriented learning therein. PolicySciences, 21, 129-168.

Teisman, G. R. (2000). Models for research into decision-making processes: On phases, streams and decision-making rounds. Public Administration, 78(4), 937-956.

Yin, R. K. (1994). Case study research: Design and methods (2nd ed.). Thousand Oaks, CA: Sage. 